\title{
KAJIAN EKONOMI DAN LINGKUNGAN AGRIBISNIS PETERNAKAN BABI DI KOTA TOMOHON (STUDI KASUS)
}

\author{
Adrie Abram Sajow*, Bobby Polii**, dan Esry Laoh** \\ Fakultas Peternakan Universitas Sam Ratulangi Manado, 95115
}

\begin{abstract}
ABSTRAK
Penelitian ini bertujuan untuk menganalisis kelayakan usaha berdasarkan kriteria investasi secara konvensional dan lingkungan, yaitu mengetahui sejauh mana kelayakan ekonomi berdasarkan kriteria investasi dengan mempertimbangkan biayabiaya internal (biaya konvensional) dan biaya eksternalilas (biaya lingkungan) dalam agribisnis peternakan babi. Penelitian ini dilaksanakan di Kota Tomohon, di mana peternakan sampel yaitu memiliki kriteria skala usaha sebesar $<1.000, \quad 1.000-5.000$ dan >5.000. Analisis yang digunakan yaitu analisis kriteria investasi untuk melihat kelayakan ekonomi usaha, dengan perhitungan Net Present Value (NPV), Benefit Cost Ratio (BCR) dan Internal Rate of Return (IRR). Nilai NPV secara konvensional ataupun secara eksternalitas ternyata lebih besar dari nol atau positif, hasil ini menunjukkan bahwa perusahaan sampel secara konvensional sudah layak secara finansial, demikian juga dengan rencana pengembangan investasi eksternalitas juga sudah layak secara finansial. Nilai IRR secara konvensional dan eksternalitas lebih besar dari satu, hasil ini menunjukkan bahwa perusahaan sampel dengan investasi konvensional dan eksternalitas masih menguntungkan,
\end{abstract}

*Mahasiswa PPS Unsrat

**Fakultas Pertanian Unsrat apalagi jika investasi ini dilihat secara lingkungan, akan lebih menguntungkan karena akan mengurangi dampak lingkungan. Nilai BC ratio secara konvensional dan eksternalitas lebih besar dari satu, hasil ini menunjukkan bahwa pengembangan investasi eksternalitas layak dilanjutkan.

Kata kunci: Ekonomi, Lingkungan, Peternakan Babi, Tomohon

\section{ABSTRACT}

ECONOMIC AND ENVINONMENT AGRIBUSINESS IN TOMOHON CITY. (CASE STUDY).This study aims to analyze the feasibility of conventional (private) and environment (externalities) investment criteria, which determine the extent of the economic feasibility of the externalities investment criteria taking into account the private costs (conventional costs) and externalities costs (environmental costs) in the pig farm agribusiness. This research was conducted in Tomohon, where the sample pig farms that have business scale criterion of $<1,000,1,000-5,000$, and $>$ 5,000 heads. The analysis used the analysis of investment criteria, with the calculation of Net Present Value (NPV), Benefit Cost Ratio (BCR) and Internal Rate of Return (IRR). NPV of conven-

tionally and externalities was greater than zero or positive, these results suggest that the companies have been conventionally sampled financially feasibility, as well as the investment plan of externalities. IRR conventional and externalities is greater 
than one, these results indicate that the samples with conventional and externalities investment companies are still profitable, especially if the investment is viewed in the environment, it would be beneficial as it will reduce the environmental impact. $\mathrm{BC}$ ratio values conventionally and externalities is greater than one, these results suggest that the externalities investment is feasible for conducting.

\section{Keywords : Economic, Environment,} Pig Farming, Tomohon

\section{PENDAHULUAN}

Pembangunan peternakan ditujukan untuk mewujudkan penyediaan dan keamanan pangan yang berwawasan lingkungan dan berkelanjutan dengan mengoptimalkan pemanfaatan sumberdaya lokal sudah menjadi tuntutan global dewasa ini, sehingga visi Direktorat Jenderal Peternakan dan Kesehatan Hewan Tahun 2010-2014 yaitu mewujudkan peternakan dan kesehatan hewan yang berdaya saing dan berkelanjutan dengan mengoptimalkan pemanfaatan sumberdaya lokal untuk mewujudkan penyediaan dan keamanan pangan hewani serta meningkatkan kesejah-teraan peternak.

Dalam rangka mewujudkan peternakan yang berbasis agribisnis maka pengembangan peternakan merupakan alternatif yang perlu diperhitungkan dengan didasarkan pada sumberdaya, dan walaupun pengembangan agribisnis ternak babi terbatas karena faktor sosial budaya (agama) tetapi di Sulawesi Utara khususnya Tomohon mempunyai prospek yang baik karena adanya permintaan pasar lokal dan daerah sekitarnya yang tinggi, serta tidak ada kendala sosial budaya.

Populasi ternak besar yang terdiri dari sapi, kuda, kambing, dan babi pada tahun 2011 berdasarkan data Tomohon Dalam Angka Tahun 2012, secara berturut-turut adalah 2.976 ekor, 277 ekor, 895 ekor, dan 73.620 ekor, di mana populasi terbanyak yaitu ternak babi. Hal ini menunjukkan ternak babi merupakan salah satu komoditas ternak yang perlu dikembangkan serta mendapat perhatian pemerintah karena mampu menghasilkan produk daging yang bernilai gizi tinggi serta harganya dapat dijangkau masyarakat. 
Pengembangan dan meningkat-kan produktivitas usaha ternak babi dengan mempertimbangkan faktor lingkungan, maka perlu dilakukan suatu kajian melalui penelitian tentang analisis ekonomi agribisnis ternak babi berbasis lingkungan secara konvensional (privat) dan analisis eksternalitas (lingkungan), berdasar-kan kriteria-kriteria investasi ternak babi di Kota Tomohon.

Berdasarkan latar belakang maka dapatlah dirumuskan masalah penelitian sebagai berikut: (1) Seberapa besar biaya internal (biaya konvensional), biaya eksternal (biaya lingkungan), dan keuntungan dalam agribisnis peternakan babi di Kota Tomohon; dan (2) Sejauh mana kelayakan ekonomi berdasarkan kriteria investasi dengan mempertimbangkan biaya-biaya internal (biaya konvensional) dan biaya eksternal (biaya lingkungan) dalam agribisnis ternak babi di Tomohon.

\section{MATERI DAN METODE PENELITIAN}

Penelitian ini telah dilaksanakan pada usaha peternakan babi di Kota Tomohon secara studi kasus terhadap pemilik usaha atau pengusaha ternak babi sebagai unit penelitian di Kota Tomohon. Metode penilaian ekonomi menggunakan data primer berdasarkan borang kaji selidik (questionairres) yang telah disusun sesuai dengan objektif kajian (Hidayatullah, dkk., 2011).

Penentuan lokasi desa sampel dan perusahaan sampel dilakukan secara "purposive sampling" menurut petunjuk Singarimbun dan Effendi (1995). Desa sampel dipilih dengan kriteria desa/kelurahan yang memiliki populasi ternak babi yang banyak dan terdapat peternak komersial. Perusahaan yang diambil dan dikaji secara studi kasus (case study) yaitu perusahaan peternakan babi yang memiliki populasi ternak babi terbanyak, dengan kriteria perusahaan telah berusaha minimal dua tahun dan jumlah ternak yang dipelihara sesuai skala usaha sebesar <1.000, 1.0005.000 dan $>5.000$, di mana pada setiap skala usaha masing-masing dipilih satu peternak. 
Definisi Operasional

Variabel Penelitian teridiri dari:

1. Biaya Total (Total Cost) adalah semua jenis-jenis biaya yang dikeluarkan dalam proses produksi, baik berupa biaya variabel, biaya tetap dan biaya lainnya yang menunjang proses produksi dalam usaha ternak babi dan sudah termasuk biaya eksternalitas, dihitung dalam Rp/tahun.

2. Biaya eksternalitas (Externalities Cost) adalah semua biaya sosial lingkungan baik yang sudah dikeluarkan dalam proses produksi maupun yang belum dikeluarkan namun dinilai secara moneter (monetary value) sebagai biaya seperti : biaya penanganan limbah, kerugian masyarakat sekitar akibat pencemaran limbah baik di tanah, sungai dan udara, meningkatnya populasi lalat dan sebagainya, di hitung dalam Rp/tahun.

3. Penerimaan Total (Benefit) adalah semua jenis penerimaan dalam usaha utama (ternak babi) seperti penjualan ternak potong dan ternak bibit dan sudah termasuk penerimaan lingkungan dari hasil penjualan by-product/wasteproduct, di hitung dalam $\mathrm{Rp} /$ tahun.

4. Penerimaan Lingkungan (Externalities/Environment Benefit) adalah semua jenis penerimaan dari hasil penjualan by-product/wasteproduct, seperti nilai moneter dari pupuk kandang dan kompos yang terjual maupun yang belum dijual, serta nilai moneter dari keuntungan lingkungan bagi masyarakat sekitar, di hitung dalam Rp/tahun.

Model analisis ekonomi dalam penelitian ini difokuskan pada analisis cost-benefit analysis (CBA) dengan memperhitungkan biaya eksternalitas dan keuntungan lingkungan di dalamnya. Analisis cost-benefit analysis yang digunakan yaitu berdasarkan kriteria-kriteria investasi untuk melihat kelayakan ekonomi usaha, yang didahului dengan perhitungan cash flow (arus tunai) usaha selama satu tahun produksi dan dilanjutkan dengan perhitungan Benefit Cost Ratio (BCR), selain Net Present Value (NPV) dan Internal 


\begin{abstract}
Rate of Return (IRR) dengan memperhitungkan biaya eksternalitas dan keuntungan lingkungan di dalamnya dengan memasukkan biaya-biaya eksternalitas dampak lingkungan dalam perhitungan biaya total dan memasukkan pendapatan lingkungan dari harga dan nilai moneter dari produk ikutan (by product) dan produk limbah (waste product).
\end{abstract}

$$
\text { Dengan dimasukkannya }
$$
biaya eksternalitas dan pendapatan lingkungan dalam model analisis finansial di atas menurut Abelson (1980), maka untuk penelitian ini PV benefit didasarkan pada perhitungan benefit (pendapatan) dan cost (biaya) sebagai berikut : Benefit $=$ nilai produksi + nilai $b y$ and waste product

Cost $=$ biaya + biaya eksternalitas

Sehingga perhitungan BC Ratio, menjadi :

Environment $B C$ Ratio $=\frac{P V(\text { Benefit }+ \text { Waste Value })}{P V(\text { Cost }+ \text { Externalities })}$

Di mana :

Environment $\mathrm{BC}$ Ratio $=$ Perbandingan antara Penerimaan dan Biaya memasukkan biaya eksternalitas dan penerimaan lingkungan dalam perhitungan.

Externalities PV Benefit $=$ Nilai sekarang dari penerimaan yang nanti diperoleh pada periode mendatang memasukkan penerimaan lingkungan dalam perhitungan.

Externalities PV Cost $=$ Nilai sekarang dari biaya yang nanti dikeluarkan pada periode mendatang memasukkan biaya eksternalitas dalam perhitungan.

Demikian juga perhitungan benefit (pendapatan) dan cost (biaya) untuk perhitungan Externalities NPV dan Externalities IRR.

\section{HASIL DAN PEMBAHASAN}

\section{Karakteristik perusahaan peternakan sampel}

Perusahaan peternakan babi yang menjadi sampel penelitian berada di Kecamatan Tomohon Utara dan Kecamatan Tomohon Barat, karena wilayah ini ditetapkan sebagai kawasan sentra produksi peternakan di Kota Tomohon. Berdasarkan penjelasan Kepmentan No. 404/kpts /OT.210/6/2002 tentang Pedoman Perizinan dan Pendaftaran Usaha Peternakan, bahwa yang tergolong perusahaan peternakan babi yaitu skala usaha >125 ekor. Dari kedua 
kecamatan tersebut diambil perusahaan peternakan babi sampel berdasarkan kriteria skala usaha yaitu $<1.000$ ekor, 1.0005.000 ekor, dan $>5.000$ di mana masing-masing skala usaha diambil satu peternak yang mewakili.

Ketiga perusahaan peternakan babi yang menjadi sampel merupakan usaha milik sendiri, dengan kapasitas produksi masing-masing sebesar 500, 2.000, dan 7.000 ekor yang berdasarkan Kepmentan No. 404/kpts/OT.210/6/2002 ketiga peternakan sampel sudah tergolong perusahaan yang harus memiliki izin usaha peternakan. Kapasitas kandang ketiga perusahaan sampel lebih dari 500 ekor tentu sudah direncanakan

Tabel 1. Karakteristik perusahaan peternakan

\begin{tabular}{|c|c|c|c|c|}
\hline No. & Uraian & Peternakan A & Peternakan B & Peternakan C \\
\hline (1) & (2) & (3) & (4) & (5) \\
\hline 1. & Status usaha & Milik Sendiri & Milik sendiri & Milik Sendiri \\
\hline 2. & Lama usaha & 5 Tahun & 8 Tahun & 25 Tahun \\
\hline 3. & Luas area & 0,75 ha & 1 ha & 5 ha \\
\hline 4. & Jumlah bangunan kantor & 1 unit & 1 unit & 1 unit \\
\hline 5. & Jumlah bangunan gudang & 1 unit & 2 unit & 3 unit \\
\hline 6. & Konstruksi kandang & Permanen & Permanen & Permanen \\
\hline 7. & Kapasitas tampung & 500 ekor & 2.000 ekor & 7.000 ekor \\
\hline \multirow{8}{*}{$\begin{array}{l}8 . \\
9 .\end{array}$} & Luas kandang & $310 \mathrm{~m}^{2}$ & $1.044 \mathrm{~m}^{2}$ & $3.228 \mathrm{~m}^{2}$ \\
\hline & Jumlah kandang: & & & \\
\hline & - Kandang Induk & 15 unit & 56 unit & 160 unit \\
\hline & - Kandang Pejantan & 2 unit & 7 unit & 20 unit \\
\hline & - Kandang Starter & 2 unit & 5 unit & 25 unit \\
\hline & - Kandang Grower & 4 unit & 7 unit & 25 unit \\
\hline & - Kandang Finisher & 8 unit & 32 unit & 100 unit \\
\hline & - kandang karantina & 1 unit & 5 unit & 12 unit \\
\hline 10. & $\begin{array}{l}\text { Tempat penyaluran air } \\
\text { limbah }\end{array}$ & $\begin{array}{l}\text { Tanggul/ } \\
\text { Sungai }\end{array}$ & $\begin{array}{l}\text { Tanggul/ } \\
\text { Sungai }\end{array}$ & $\begin{array}{l}\text { Tanggul dan } \\
\text { Drainase } \\
\text { Buatan }\end{array}$ \\
\hline \multirow[t]{3}{*}{11.} & Jarak kandang dengan : & & & \\
\hline & $\Rightarrow$ pemukiman & $500 \mathrm{~m}$ & $150 \mathrm{~m}$ & $950 \mathrm{~m}$ \\
\hline & $\Rightarrow$ jalan raya & $50 \mathrm{~m}$ & $30 \mathrm{~m}$ & $100 \mathrm{~m}$ \\
\hline 12. & Sumber air & Mata air & Sumur pompa & $\begin{array}{l}\text { Sumur } \\
\text { pompa }\end{array}$ \\
\hline \multirow{3}{*}{$\begin{array}{l}13 . \\
14 .\end{array}$} & Tenaga Listrik & PLN/Genset & PLN & PLN \\
\hline & $\begin{array}{l}\text { Tenaga Kerja: } \\
\text { - Manajer } \\
\text { - Tenaga Kerja kelu }\end{array}$ & 1 ora & 1 orang pria & 1 orang pria \\
\hline & - Tenaga Kerja luar kelua & 1 orang pria & 4 orang pria & 15 orang pria \\
\hline
\end{tabular}

Sumber: Diolah dari data primer, 2013.

sesuai lokasi dan ketersediaan sumberdaya dan dana. Karakteristik ketiga usaha peternakan babi sampel dapat dilihat pada Tabel 1.Kandang 
merupakan hal yang sangat penting dalam menunjang usaha, dan untuk memudahkan tatalaksana seperti memberi makan, memandikan ternak babi dan mengontrol penyakit serta memberikan kenyamanan pada ternak (Anonimous, 2010). Selain itu kandang juga harus memberikan kenyamanan bagi manusia.

\begin{tabular}{lll}
\multicolumn{1}{c}{ Namun } & di antara & ketiga \\
perusahaan & sampel, & hanya \\
Perusahaan C & yang telah cukup \\
representatif & & memberikan
\end{tabular}
kenyamanan bagi manusia baik peternak dan tenaga kerjanya, maupun masyarakat sekitar. Pada ketiga peternakan sampel hanya Perusahaan $\mathrm{C}$ yang masih memiliki areal untuk peningkatan kapasitas usaha, sehingga masih memungkinkan investasi konstruksi kandang untuk pengembangan usaha.

Konstruksi kandang pada ketiga peternakan sampel sudah ada bagian yang perlu direnovasi sehingga perlu mengeluarkan biaya investasi terutama untuk biaya eksternalitas.

Limbah kotoran ternak babi di lokasi perkandangan pada ketiga perusahaan peternakan babi sampel disalurkan ke tempat penampungan limbah, kemudian sebagian limbah kotoran ternak dari tempat penampungan dipindahkan ke karung-karung untuk dipergunakan sebagai pupuk kandang. Penyaluran air limbah dari perkandangan ke tempat penampungan limbah dan dibiarkan meresap ke dalam tanah, dan sebagian kecil mengalir ke sungai. Penataan saluran air limbah kandang pada perusahaan peternakan C sudah cukup baik, namun pada dua perusahaan A dan B masih perlu ditingkatkan. Hal ini perlu ditingkatkan karena pada kedua perusahaan ini masih menyebarkan bau yang relatif jauh bahkan sampai ke jalan raya, sehingga agak mengganggu masyarakat sekitar maupun pengguna jalan raya.

\section{Biaya Produksi, Penerimaan dan Keuntungan}

Untuk kajian eksternalitas, biaya produksi dalam suatu usaha terdiri dari biaya langsung dan tidak langsung. Biaya langsung yaitu biaya yang berhubungan langsung dengan kepentingan produksi, seperti biaya karena lokasi dan menataan drainase 
yang lebih representatif sehingga investasi (biaya pembangunan konstruksi, biaya peralatan), biaya operasi dan pemeliharaan (biaya penyusutan, bunga bank, tanah, modal

kerja, biaya lain). Sedangkan biaya tidak langsung yaitu biaya yang perlu diperhitungkan dalam menganalisis proyek yang dikenal dengan biaya eksternalitas (biaya penanganan pencemaran, bau, dll).

Berdasarkan hasil penelitian para peternak babi sampel di Kota Tomohon mengeluarkan biaya produksi ekternalitas yaitu biaya investasi dan operasional secara konvensional dan biaya eksternalitas.

Komposisi biaya usaha peternakan babi sampel di Kota Tomohon dapat dilihat pada Tabel 2.

Tabel 2. Komposisi Biaya Usaha Peternakan Babi Sampel di Kota Tomohon Tahun 2013

\begin{tabular}{|c|c|c|c|}
\hline \multirow{2}{*}{ Perusahaan } & \multirow{2}{*}{ Komponen Biaya } & \multicolumn{2}{|c|}{ Jumlah Biaya } \\
\hline & & $\mathbf{R p}$ & $\%$ \\
\hline \multirow{14}{*}{ Perusahaan A } & Di & (3) & (4) \\
\hline & Biaya Tetap: & & \\
\hline & - Penyusutan Kandang/Peralatan & 5.356 .500 & 1,33 \\
\hline & - Nilai Sewa Tanah & 15.500 .000 & 3,84 \\
\hline & - Listrik & 1.600 .000 & 0,40 \\
\hline & - PBB, Pajak Usaha, Retribusi, d11 & 790.000 & 0,20 \\
\hline & Biaya Variabel: & & \\
\hline & - Biaya Bibit & 3.100 .000 & 0,74 \\
\hline & - Biaya Pakan & 337.827 .264 & 83,77 \\
\hline & - Biaya Obat dan Vaksin & 753.060 & 0,19 \\
\hline & - Transportasi & 10.950 .000 & 2,72 \\
\hline & - Biaya Tenaga Kerja & 25.925 .000 & 6,43 \\
\hline & Biaya Eksternalitas & 1.587 .500 & 0,39 \\
\hline & Total & 403.289 .324 & 100,00 \\
\hline \multirow[t]{12}{*}{ Perusahaan B } & Biaya Tetap: & & \\
\hline & - Penyusutan Kandang/Peralatan & 21.524 .000 & 0,73 \\
\hline & - Nilai Sewa Tanah & 55.000 .000 & 1,87 \\
\hline & - Listrik & 7.200 .000 & 0,25 \\
\hline & $\begin{array}{l}\text { - PBB, Pajak Usaha, Retribusi, d11 } \\
\text { Biaya Variabel: }\end{array}$ & 101.816 .850 & 3,47 \\
\hline & & 22.500 .000 & 0,77 \\
\hline & - Biaya Pakan & 2.617 .659 .423 & 89,17 \\
\hline & - Biaya Obat dan Vaksin & 753.060 & 0,03 \\
\hline & - Transportasi & 18.250 .000 & 0,62 \\
\hline & - Biaya Tenaga Kerja & 63.125 .000 & 2,15 \\
\hline & Biaya Eksternalitas & 27.875 .000 & 0,95 \\
\hline & Total & 2.935 .703 .333 & 100,00 \\
\hline \multirow[t]{12}{*}{ Perusahaan $\mathbf{C}$} & Biaya Tetap: & & \\
\hline & - Penyusutan Kandang/Peralatan & 67.930 .000 & 0,80 \\
\hline & - Nilai Sewa Tanah & 170.000 .000 & 2,01 \\
\hline & - Listrik & 14.500 .000 & 0,17 \\
\hline & $\begin{array}{l}\text { - PBB, Pajak Usaha, Retribusi, dll } \\
\text { Biaya Variabel: }\end{array}$ & 290.940 .818 & 3,44 \\
\hline & - Biaya Bibit & 67.500 .000 & 0,80 \\
\hline & - Biaya Pakan & 7.592 .879 .721 & 89,73 \\
\hline & - Biaya Obat dan Vaksin & 25.506 .000 & 0,30 \\
\hline & - Transportasi & 18.250 .000 & 0,22 \\
\hline & - Biaya Tenaga Kerja & 181.925 .000 & 2,15 \\
\hline & Biaya Eksternalitas & 19.875 .000 & 0,23 \\
\hline & Total & 8.461 .556 .539 & $1 \mathrm{OO}, \mathrm{OO}$ \\
\hline
\end{tabular}

Sumber: Diolah dari data primer, 2013. 
Tabel 2 menunjukkan ketiga perusahan ternak babi sampel masing-masing mengeluarkan biaya pakan sebagai biaya terbesar yaitu sebesar $83,77 \%, \quad 89,17 \%$ dan $89,73 \%$. Hal ini ternyata lebih besar dibanding dengan yang dikatakan oleh Sihombing (1997), bahwa 60$80 \%$ dari biaya dihabiskan untuk biaya pakan. Penyebabnya karena makin mahalnya harga bahan baku dan konsentrat di pasaran, sehubungan dengan kenaikan hargaharga berbagai bahan yang disebabkan oleh kenaikan harga BBM dan tingkat inflasi.

Biaya eksternalitas pada ketiga peternakan masih sangat rendah, di mana pada ketiga perusahan ternak babi sampel hanya mengeluarkan biaya lingkungan sebagai biaya eksternalitas masingmasing sebesar 0,39\% (Perusahaan A), $0,95 \%$ (Perusahaan B) dan 0,23\% (Perusahaan C). Dari ketiga perusahaan tersebut, justru perusahaan

Tabel 3. Biaya, Penerimaan dan Keuntungan Konvensional dan Eksternalitas Usaha Peternakan Babi Sampel di Kota Tomohon Tahun 2013

\begin{tabular}{clrcr}
\hline \multirow{2}{*}{ PERUSAHAAN } & \multirow{2}{*}{ URAIAN } & \multicolumn{3}{c}{ Jumlah (Rp/Thn) } \\
\cline { 3 - 5 } & & Konvensional & Eksternalitas & \multicolumn{1}{c}{ Total } \\
\hline \multirow{2}{*}{ Perusahaan A } & (2) & \multicolumn{1}{c}{$(3)$} & $(4)$ & $(5)=(3)+(4)$ \\
\cline { 2 - 5 } & Biaya Produksi & 401.701 .824 & 1.587 .500 & 403.289 .324 \\
\cline { 2 - 5 } Keuntungan & 76.611 .176 & 2.384 .500 & 77.408 .176 \\
\hline \multirow{3}{*}{ Perusahaan B B } & Penerimaan & 4.056 .545 .000 & 9.752 .000 & 4.066 .270 .000 \\
& Biaya Produksi & 2.907 .828 .333 & 27.875 .000 & 2.935 .703 .333 \\
\cline { 2 - 5 } Perusahaan C & Keuntungan & 1.148 .716 .667 & $(-18.150 .000)$ & 1.102 .691 .667 \\
\cline { 2 - 5 } & Benerimaana Produksi & 11.642 .272 .800 & 22.500 .000 & 11.664 .772 .800 \\
\cline { 2 - 5 } & Keuntungan & 3.200 .591 .681 .539 & 19.875 .000 & 8.461 .556 .539 \\
\hline
\end{tabular}

Sumber: Diolah dari data primer, 2013. 
dengan kapasitas produksi paling kecil biaya eksternalitasnya, hal ini biaya lingkungan yang dikeluarkan besar yaitu Perusahaan $\mathrm{C}$ yang paling lebih sedikit prosentasenya dibanding yang lainnya.penerimaan dan keuntungan lingkungan di dalamnya pada usaha peternakan babi sampel di Kota Tomohon, sebagaimana dapat

dilihat Kajian ekonomi dalam penelitian ini difokuskan pada analisis cost-benefit analysis (CBA) dengan memperhitungkan biaya eksternalitas,

pada Tabel 3 menunjukkan bahwa analisis secara konvensional (private), ketiga perusahaan sampel memperolehkeuntungan selama setahun pada tahun $2013\left(\mathrm{~T}_{0}\right)$ masing-masing sebesar Rp.76.611.176 (Perusahaan A), Rp.1.148.716.667 (Perusahaan B) dan Rp.3.200.591.261 (Perusahaan C). Namun secara terpisah, melalui perhitungan penerimaan dan biaya lingkungan (eksternalitas) menunjukkan bahwa perusahaan $\mathrm{B}$ tidak memperoleh keuntungan, bahkan justru mengalami kerugian sebesar Rp.18.150.000.

Hasil tersebut terjadi karena perusahaan tersebut memperoleh penerimaan lingkungan yaitu nilai jual pemanfaatan pupuk kandang untuk pertanian hanya sebesar Rp.9.752.000 sementara itu perusahaan mengeluarkan biaya korbanan sebesar Rp.27.875.000 untuk mengeliminir dampak lingkungan demi keberlanjutan usahanya.

Sebab kalau tidak demikian, dampak limbah akan menganggu lingkungan, sehingga akan dikomplain oleh masyarakat atau bahkan masyarakat akan meminta untuk menghentikan peternakan di lokasi tersebut yang.dapat berakibat peternak akan makin merugi.

Hasil analisis eksternalitas dengan penerimaan dan biaya kombinasi secara konvensional maupun lingkungan, menunjukkan bahwa ketiga perusahaan memperoleh keuntungan selama setahun masing-masing sebesar Rp.77.408.176 (Perusahaan A), Rp.1.102.691.667 (Perusahaan B) 
dan Rp.3.183.341.261 (Perusahaan

C). Hal ini berarti bahwa sekalipun peternak mengorbankan dana untuk biaya lingkungan, namun masih tetap memberikan keuntungan finansial bagi usahanya. Untuk itu perlu dilakukan analisis finansial selama 10 tahun ke depan (2014-2023), untuk melihat prospek kelayakan usaha dengan meningkatkan investasi untuk biaya eksternalitas melalui analisis kriteria investasi ekternalitas usaha peternakan babi sampel di Kota Tomohon yang akan dibahas selanjutnya.

\section{Analisis Kriteria Investasi}

Ekternalitas Usaha Peternakan Babi di Kota Tomohon

\begin{tabular}{llr}
\multicolumn{1}{c}{ Penelitian } & ini & akan \\
mengevaluasi & & rencana \\
pengembangan & secara & eksternalitas
\end{tabular}

(externalities) yaitu dengan memperhitungkan rencana investasi biaya lingkungan dan penerimaan ataupun nilai tambah (value added) secara lingkungan (externalities) bersamaan dengan perhitungan secara konvensional (private), untuk melihat apakah dengan investasi lingkungan akan layak secara finansial. Penelitian ini menggunakan tiga kriteria investasi yang pertama, yaitu NPV, IRR dan BC Ratio, dilakukan analisis finansial selama 10 tahun ke depan (2014-2023) berdasarkan data $T_{0}$ Tahun 2013, untuk melihat prospek kelayakan usaha dengan meningkatkan investasi untuk biaya eksternalitas melalui analisis kriteria investasi ekternalitas usaha peternakan babi sampel di Kota Tomohon.

Tabel 4. Hasil Analisis Kriteria Investasi Eksternalitas Usaha Peternakan Babi Sampel di Kota Tomohon

\begin{tabular}{|c|c|c|c|c|}
\hline \multirow{2}{*}{$\begin{array}{c}\text { Perusahaan } \\
\text { (1) }\end{array}$} & \multirow{2}{*}{ Indikator } & \multicolumn{2}{|c|}{ Hasil Analisis } & \multirow{2}{*}{ Ket. } \\
\hline & & $\begin{array}{c}\text { Konvensional } \\
\text { (3) }\end{array}$ & $\begin{array}{c}\text { Eksternalitas } \\
\text { (4) }\end{array}$ & \\
\hline \multirow{5}{*}{ Perusahaan A } & NPV $10 \%$ & 6.100 .340 .492 & 6.114 .790 .115 & \multirow{5}{*}{ Go } \\
\hline & NPV15\% & 4.779 .981 .750 & 4.792 .552 .532 & \\
\hline & IIRR & 33,10 & 33,12 & \\
\hline & BCR $_{10 \%}$ & 2,99 & 2,99 & \\
\hline & BCR $15 \%$ & 2,82 & 2,81 & \\
\hline \multirow{5}{*}{ Perusahaan B } & NPV $10 \%$ & 13.061 .327 .035 & 12.772 .053 .345 & \multirow{5}{*}{ GO } \\
\hline & NPV $15 \%$ & 10.655 .455 .862 & 10.429 .580 .618 & \\
\hline & IRR & 37,14 & 37,26 & \\
\hline & BCR $_{10 \%}$ & 1,60 & 1,58 & \\
\hline & $\mathrm{BCR}_{15 \%}$ & 1,57 & 1,55 & \\
\hline \multirow{5}{*}{ Perusahaan C } & NPV $10 \%$ & 26.666 .910 .038 & 26.495 .338 .085 & \multirow{5}{*}{ Go } \\
\hline & NPV $15 \%$ & 22.045 .047 .735 & 21.898 .703 .065 & \\
\hline & IRTR & 38,85 & 38,82 & \\
\hline & BCR $_{10 \%}$ & 1,43 & 1,42 & \\
\hline & BCR $_{15 \%}$ & 1,41 & 1,40 & \\
\hline
\end{tabular}

Sumber: Diolah dari data primer, 2013. 
Investasi lingkungan yang direncanakan para peternak sampel yaitu penataan kandang dan saluran pembuangan limbah kotoran ternak, terutama tanggul ataupun bak penampungan kotoran ternak yang berfungsi semacam septic tank untuk mengfermentasi dan mengurai kotoran ternak untuk menjadi slurry dan limbah cair yang dapat dialirkan ke saluran kali. Namun dari keterangan para responden bahwa pembuatan konstruksi ini direncanakan pada waktu yang berbeda dan dengan kemampuan dana yang dimiliki.

\section{Hasil analisis externalities} cash flow yang dianalisis secara kriteria investasi sebagaimana dapat dilihat pada Tabel 4 menunjukkan nilai NPV ketiga perusahaan pada tingkat discount factor $10 \%$ secara konvensional ataupun secara eksternalitas ternyata lebih besar dari nol atau positif. Demikian juga nilai NPV pada tingkat discount factor $15 \%$ secara konvensional ataupun secara eksternalitas lebih besar dari nol atau positif.

Hasil ini menunjukkan bahwa ketiga perusahaan sampel secara konvensional memberikan pendapatan atau benefit yang lebih besar dari nol artinya sudah layak secara finansial, demikian juga dengan rencana investasi eksternalitas memberikan pendapatan atau benefit yang lebih besar dari nol artinya juga sudah layak secara finansial. Berdasarkan kriteria investasi hasil analisis ini menunjuk-kan bahwa pengembangan investasi eksternalitas pada perusahaan peternakan babi sampel di Kota Tomohon secara finansial layak untuk dilaksanakan.

Hasil analisis IRR pengembangan peternakan babi di Kota Tomohon untuk satu sampai sepuluh tahun mendatang dengan tingkat diskonto (discout factor) $10 \%$ dan $15 \%$ sesuai dengan kisaran tingkat bunga pasar berlaku sebagaimana dapat dilihat pada Tabel 4, menunjukkan nilai IRR ketiga perusahaan secara konvensional ternyata lebih besar dari satu, yaitu masing-masing sebesar 33,10\%, $37,14 \%$ dan 38,85\%. Demikian juga secara eksternalitas ternyata lebih besar dari satu, yaitu masing-masing sebesar $33,12 \%, \quad 37,26 \%$ dan $38,82 \%$, hasil ini menunjukkan bahwa ketiga perusahaan sampel dengan investasi eksternalitas pada pengembangan peternakan babi di 
Kota Tomohon selama sepuluh tahun ke depan dapat memberikan tingkat keuntungan finansial.

Hasil ini menunjukkan bahwa rencana pengembangan investasi eksternalitas peternakan babi di Kota Tomohon dapat memberikan tingkat keuntungan secara finansial, di mana investasi eksternalitas pengembangan peternakan babi masih menguntung-kan, apalagi secara lingkungan akan lebih menguntungkan karena akan mengurangi dampak lingkungan.

Hasil analisis BC ratio pengembangan investasi eksternalitas sebagaimana dapat dilihat pada Tabel 4, menunjukkan nilai $\mathrm{BC}$ ratio ketiga perusahaan pada tingkat discount factor $10 \%$ secara konvensional ataupun secara eksternalitas ternyata lebih besar dari satu. Demikian juga nilai $\mathrm{BC}$ ratio pada tingkat discount factor $15 \%$ secara konvensional ataupun secara eksternalitas lebih besar dari satu.

Hasil ini menunjukkan bahwa ketiga perusahaan sampel secara konvensional memberikan perbandingan antara pendapatan atau benefit dengan biaya investasi yang lebih besar dari satu artinya sudah layak secara finansial, demikian juga dengan rencana investasi eksternalitas memberikan perbandingan antara pendapatan atau benefit dengan biaya investasi yang lebih besar dari satu.

Berdasarkan kriteria investasi hasil analisis ini menunjukkan bahwa pengembangan investasi eksternalitas pada perusahaan peternakan babi sampel di Kota Tomohon layak untuk dilaksanakan, dilanjutkan atau dikembangkan.

\section{KESIMPULAN}

Analisis finansial investasi eksternalitas perusahaan peternakan babi di Kota Tomohon memberikan Nilai NPV, Nilai IRR, dan Nilai BC ratio yang masih menguntungkan, baik secara konvensional maupun secara investasi eksternalitas atau lingkungan. Dengan demikian pengembangan investasi lingkungan layak dilanjutkan atau dikembangkan

\section{SARAN}

Para pengusaha peternakan babi supaya melakukan investasi eksternalitas terutama konstruksi 
prasarana lingkungan, untuk mengeliminir dampak negatif limbah kotoran ternak babi dan menghindari resistensi masyarakat sekitar. Disarankan juga supaya pemerintah menegakkan aturan dengan mengharuskan perusahaan peternakan babi melakukan investasi eksternalitas, untuk menanggulangi dampak lingkungan.

\section{DAFTAR PUSTAKA}

About.com, 2013. Definition of Externality. http://economics. about.com/cs/economicsgloss ary/g/externality.htm diakses tgl 1 Juni 2013.

Anonimous, 2002. Keputusan Menteri Pertanian Nomor 404/kpts/OT.210/6/2002

tentang Pedoman Perizinan dan

Pendaftaran Usaha Peternakan. Departemen Pertanian, Jakarta.

Anonimous, 2009. Undang-Undang

Republik Indonesia Nomor 32

Tahun $2009 \quad$ Tentang

Perlindungan Dan Pengelolaan

Lingkungan Hidup. Sekretariat Negara Republik Indonesia, Jakarta.
AAK, 2007. Pedoman Lengkap Beternak Babi. Kanisius, Yogyakarta.

Abelson, P., 1980. Cost Benefit Analysis and Environmental Problems. Gower Publishing Company Limited, New South Wales.

Andayani, 2005. Tanggung Jawab Lingkungan dan Informasi Biaya Lingkungan. Ekuitas 9(2):169-194. BPP-SDM Deptan. Penataan Lokasi Usaha Babi yang Ramah Lingkungan. Pusat Penyulu-han Pertanian, Badan Penyu-luhan dan Pengembangan SDM Pertanian.

http://cybex.deptan.go.id/penyulu han/penataan-lokasi-usaha-babiyang-ramah-lingkungan diakses $\operatorname{tgl} 31$ Mei 2013.

Dewi, H.I., 2011. Upaya Adjustment dan Adaptasi untuk Mengatasi Eksternalitas Ruang Negatif. Jurnal Arsitektur NALARs 10(1):39-52.

Ditjennak-KH Deptan, 2011. Rencana Strategis (Renstra) Direkto-rat Jenderal Peternakan dan Kesehatan Hewan Tahun 20102014. Direktorat Jenderal 
Peternakan dan Kesehatan Hewan Kementerian Pertanian, Jakarta.

Ditjennak-KH Deptan, 2012. Pedoman

Pelaksanaan Penataan Usaha

Budidaya Babi Ramah Lingkungan

Tahun

2012.

http://www.deptan.go.id/pedum

2012/PETERNAKAN/1.8.1.\%20Pe

dum\%20pemberdayaan\%20babi\%2

02012.pdf diakses tgl 28 Mei 2013.

Gittinger, J.P. 1982. Economic

Analysis of Agricultural Projects

(Terje-mahan). UI Press. Jakarta.

Hidayatullah, T., R.Y. Suryandari,

A.C. Fitriyanto, dan I. Nahib,

2011. Pemetaan neraca dan

valuasi ekonomi sumber daya

pulau kecil. Geografia OnlineTM

Malaysia Journal of Society and Space 7(1):87-92.

Kadariah, Karlina L. dan C. Gray. 1999. Pengantar Evaluasi Proyek.

Fakultas Ekonomi Universitas Indonesia. Jakarta.
Mulyaningrum, 2005. Eksternalitas

Ekonomi Dalam Pembangunan

Wisata Alam Berkelanjutan.

Jurnal Penelitian UNIB 9(1):9-20.

Owen, A.D., 2004. Environmental Externalities, Market Distortions and The Economics of Renewable Energy Technologies. The Energy Journal 25(3):9-20.

Setyawan, H., S.I. Santoso dan Mukson, 2005. Analisis Finansial Usaha Peternakan Sapi Perah Pada Tingkat Perusahaan Peternakan. Animal Production 7(1):40-45.

Sihombing, D., 1997. Ilmu Ternak Babi. Gadjah Mada University Press, Yogyakarta.

Singarimbun, M dan S. Effendi, 1995. Metode Penelitian Survei. LP3ES. Jakarta.

Umar, H. 2003. Studi Kelayakan Bisnis. PT. Gramedia Pustaka Utama. Jakarta. 